\title{
A PERSISTENTE AGENDA DO DESENVOLVIMENTO: FINANCIAMENTO DE LONGO PRAZO, INTERMEDIAÇÃO FINANCEIRA, FALHAS DE MERCADO E FALHAS GOVERNAMENTAIS ${ }^{1}$
}

Ricardo Bacelette ${ }^{2}$

\section{SINOPSE}

Em 2018, o Ipea lançou o livro Financiamento do Desenvolvimento no Brasil, que partiu de diagnósticos e pressupostos referentes aos problemas relacionados ao financiamento do desenvolvimento no país, assolado por um duplo dilema do setor: além da baixa taxa de poupança, o país possui um sistema de intermediação financeira repleto de distorçóes que obstruem tais canais de financiamento. Este texto apresenta uma discussão sobre o estado atual de alguns daqueles temas estudados de maneira aprofundada no livro.

Palavras-chave: financiamento do desenvolvimento; crédito direcionado; bancos de desenvolvimento.

DOI: http://dx.doi.org/10.38116/radar63art1

\section{INTRODUÇÃO}

O Ipea elaborou, entre 2016 e 2017, no âmbito de um projeto mais amplo de policy recommendations denominado Desafios da Nação, organizado por João De Negri, Bruno Araújo e Ricardo Bacelette - que contou com a colaboração de mais de cem especialistas do instituto, da academia, do governo e da sociedade civil -, um conjunto de medidas de políticas públicas que envolviam reformas macro e microeconômicas, com o objetivo de auxiliar o crescimento sustentado de longo prazo. Entre as diretrizes de recomendaçóes estavam: a contingência fiscal e sua necessidade de reforma, assim como a reforma das previdências tributária e trabalhista; o aperfeiçoamento dos sistemas educacional e de saúde; a necessidade de melhorias das políticas de inovação, do ambiente de negócios e de logística; as incertezas ocasionadas pelo risco regulatório e os novos modelos de concessão; e a necessidade de maior abertura e integração comercial do país com o mundo, com vistas ao aumento da eficiência alocativa e da produtividade da economia brasileira, causas estruturais de seu baixo crescimento.

De uma das vertentes do projeto, sobre financiamento de longo prazo, surgiu um projeto mais aprofundado, intitulado Financiamento do Desenvolvimento no Brasil (De Negri, Araújo e Bacelette, 2018). O trabalho partiu de diagnósticos e pressupostos referentes aos problemas relacionados ao financiamento do desenvolvimento no país, assolado por um duplo dilema do setor: além da baixa taxa de poupança, o país possui um sistema de intermediação financeira repleto de distorçóes que obstruem tais canais de financiamento. A carência de mecanismos privados de financiamento de longo prazo e a ineficiência do mercado de crédito no Brasil tornam os juros do crédito livre mais elevados, por vezes inviabilizando investimentos em capital, infraestrutura, inovação e outros projetos

1. Este trabalho revisa e discute pontos do livro Financiamento do Desenvolvimento do Brasil (De Negri, Araújo e Bacelette, 2018) e pode conter passagens literais da obra, bem como do sumário apresentado no texto Desafios da Nação (Ipea, 2018).

2. Técnico de planejamento e pesquisa na Diretoria de Estudos e Políticas Setoriais de Inovação e Infraestrutura (Diset) do Ipea. 
estruturantes necessários para o incremento de produtividade. Ademais, as múltiplas intervenções que ocorreram no mercado nos últimos anos, afetando a alocação de recursos, além de intervençóes pontuais setoriais - como os setores elétrico, de transportes e portuário - e em empresas estatais, diminuíram a previsibilidade da política governamental, aumentando riscos e, assim, elevando os custos dos projetos.

Baseando-se em evidências internacionais, o trabalho discutiu como o desenvolvimento de um sistema de intermediação financeira é precondição para o desenvolvimento de um país. Comparações internacionais demonstram que o Brasil é muito mal posicionado no que tange ao indicador de profundidade financeira (financial deepness), que mede a parcela do crédito privado sobre o produto interno bruto (PIB). Entre 2013 e 2015, esse indicador se situou em torno de $50 \%$ do PIB brasileiro, enquanto essa cifra corresponde a 70\% no Chile e na África do Sul, e a quase 120\% na China. Apenas um pequeno número de empresas, geralmente de grande porte, consegue se livrar das restriçôes de crédito no mercado financeiro brasileiro. Em relação ao setor empresarial, em 2015, entre 74 países no mundo, o Brasil ocupava a $53^{a}$ posiçáo em capitalização das empresas no mercado de capitais e o $27^{\circ}$ lugar no número de empresas listadas em bolsa (359 empresas). Tais indicadores colocam o Brasil atrás de economias relativamente menores. Por sua vez, o valor médio das ofertas públicas iniciais (initial public offerings - IPOs) de açóes foi relativamente alto, US\$ 411 milhóes, o que colocava o Brasil na quinta posição relativa (Costa, 2016). Portanto, há uma concentração de capitais na bolsa de valores brasileira, que é basicamente composta por poucas e grandes empresas. Enquanto no mundo a renda variável na carteira de fundos de investimento é de aproximadamente $40 \%$, no Brasil ela é de $11 \%$. Da carteira de fundos de investimento, 66\% foram compostos por títulos públicos no Brasil em 2015 (Rocca, 2017). O problema da escassez de orçamento fiscal faz com que o governo precise competir com o setor privado pela poupança, muitas vezes forçada, e que o mercado de capitais perca sua funcionalidade para financiar o desenvolvimento.

Uma das pretensas soluçóes adotadas com maior ênfase a partir de 2011 acabou por agravar o problema de maneira circular: o substancial aumento do crédito direcionado, com menores taxas para finalidades específicas, como bens de capital e habitação, e com subsídios implícitos e explícitos por parte do Tesouro, acarretou impactos fiscais e de política monetária. Isso se deu devido à pressão sobre a taxa de juros livres pela obstrução dos canais de transmissão de políticas monetárias, visto que o crédito vinculado estava imune à Selic. Essas operaçóes, particularmente por meio do Banco Nacional de Desenvolvimento Econômico e Social (BNDES), foram ampliadas de forma sem precedente durante o chamado Programa de Sustentação do Investimento (PSI). Assim, formava-se um círculo vicioso, que tornava a taxa de juros básica cada vez mais alta e o financiamento ao desenvolvimento cada vez mais dependente de expansão fiscal e dívida pública, o que inviabilizou a queda sustentada dos juros e levou o governo e o setor privado a disputarem a poupança privada. Além disso, também foram geradas distorçôes no mercado de capitais, uma vez que o custo de oportunidade de investimento em açóes era muito mais alto em face da remuneração dada aos títulos públicos.

O crédito direcionado se expandiu no período recente basicamente via Tesouro Nacional, em razão da estrutura de funding (fontes de financiamento) desses mecanismos de intermediação financeira. Enquanto o BNDES dependia fundamentalmente do Fundo de Amparo ao Trabalhador (FAT), o impacto fiscal era menor, pois a remuneração do FAT é indexada pela taxa de juros de longo prazo (TJLP) e, até 2009, a maior parte dos empréstimos do BNDES era também indexada à TJLP mais um spread. No entanto, os recursos do Tesouro têm o custo financeiro da taxa Selic, tradicionalmente mais alta que a TJLP. Como os recursos do FAT são limitados, optou-se por ampliar os aportes do Tesouro, que seriam remunerados conforme a TJLP. A diferença da remuneração do capital da União (TJLP) pelo BNDES e da taxa pela qual a União capta recursos (Selic) pode ser considerada, então, um subsídio implícito ao setor produtivo a ser pago pela União.

Além desse subsídio implícito, há ainda o subsídio explícito, relativo às equalizaçôes de taxa de juros correspondentes a programas como o PSI, lançado em 2009. Basicamente, a equalização é definida como o diferencial entre a taxa de juros para o tomador e o custo da fonte de recursos. Sob o regime brasileiro de metas de inflação, o governo controla o nível de preços por meio dessa taxa. O problema da política monetária que resulta do estreitamento dos canais de transmissão faz com que o Banco Central do Brasil (BCB) precise elevar 
ainda mais a taxa de juros para controlar a demanda, porque metade do crédito é direcionada e "escapa" da taxa de juros do Selic. Ademais, a taxa Selic elevada tem efeito fiscal tanto sobre a dívida do governo quanto sobre os agentes econômicos que não têm acesso ao crédito subsidiado, os quais enfrentam taxas de juros maiores. Portanto, a discussão sobre crédito livre versus crédito direcionado não deve se ater somente à sua existência, ao seu volume ou às suas proporçôes. Há razóes econômicas que justificam o crédito direcionado, subsidiado ou não, e este deve ser tão grande quanto as falhas de mercado que ele pretende resolver. Devem-se avaliar os benefícios sociais da correçáo de falhas de mercado via crédito direcionado em face dos custos sociais decorrentes dessa política.

Felizmente, desde a publicação do livro Financiamento do Desenvolvimento no Brasil, várias mudanças foram implementadas de maneira a alterar algumas dessas dinâmicas. A queda da taxa de juros neutros da economia, que equilibram oferta e demanda agregadas, cedeu, em razão de três principais fatores, não exaustivos: i) ancoragem de expectativas relativas à necessidade de financiamento do Estado pelas reformas de ordem fiscal e menor custo relativo de captação no mercado; ii) redução do crédito vinculado e do efeito crowding out gerado sobre as taxas de juros livres; e iii) arrefecimento da demanda agregada em razão da fraca atividade econômica dos últimos anos, entre outros fatores. Aliadas a isso, mudanças institucionais em mecanismos de funding como os do BNDES e a reforma da TJLP, que deu lugar à taxa de longo prazo (TLP), permitiram a convergência das taxas de juros de crédito livre e vinculado.

Além da questão do custo do dinheiro na economia, a experiência internacional nos mostra que melhores práticas e arranjos institucionais podem ajudar a melhorar a eficiência alocativa, ao fornecer outros instrumentos de funding e aprimorar a governança dos bancos de desenvolvimento (BDs), tais como: emissão de títulos, obrigações e notas promissórias e/ou captaçáo de recursos no mercado privado de capitais nacional ou internacional, como é o caso do Banco de Desenvolvimento da China (China Development Bank - CDB); captação de recursos por meio de poupança e depósitos do público, no caso dos BDs múltiplos, como ocorre com o BD da Turquia; empréstimos de outras instituiçóes financeiras, praticados, sobretudo, por BDs de propriedade privada, como também ocorre no caso turco; e utilização de seu próprio patrimônio, em períodos de crises fiscais, desmobilizando ativos e dando mais liquidez à economia nacional. As duas primeiras medidas, no entanto, são consideradas indesejáveis e deletérias ao sistema financeiro de um país - pois acentuariam ainda mais o efeito crowding out exercido pelos $\mathrm{BDs}$, ao concorrer e disputar recursos com bancos privados, os quais se encontram em desvantagem por possuírem menor portfólio e não contarem com dotação orçamentária governamental -, além de contribuir para a concentração da atividade bancária.

Em razão, porém, do esgotamento dos mecanismos convencionais de funding citados anteriormente, os BDs de nova geração pelo mundo têm implementado novas modalidades para a captação de recursos, tais como: i) recirculação de lucros e paybacks (retorno dos investimentos) obtidos por BDs, com a vantagem de dar maior liquidez às suas economias e reduzir o efeito crowding out; ii) cofinanciamento para projetos específicos, por arranjos ad hoc entre os vários BDs nacionais ou entre BDs e bancos de desenvolvimento multilaterais (BDMs); iii) criação de fundos fiduciários, oferecidos por outros países, para os BDs desempenharem missóes específicas, como é o caso dos fundos canadense e norueguês para a proteção ambiental; iv) vinculação da política tributária aos BDs, destinando parte das receitas de impostos específicos, como uso de combustíveis fósseis ou exploração de recursos naturais; e $v$ ) criação de fundos especiais para setores específicos, vinculados à emissão de títulos públicos. Na experiência internacional, é usual BDs manterem o controle do desenho do projeto, do planejamento da assistência técnica necessária à sua implementação por autoridades locais, da execução de estudos de viabilidade, bem como da assistência jurídica requerida para a operação, de modo a reduzir custos de transação associados aos projetos.

Resta, no entanto, um debate ainda em aberto de ordem qualitativa: qual o papel do BNDES como indutor do desenvolvimento? Em quais setores ele poderia atuar de modo a suprir falhas de mercado? Projetos estruturantes para a economia brasileira, como nas áreas de energia, transportes, infraestrutura urbana, mobilidade etc., têm maturação longa. Um porto, uma ponte ou uma estrada por vezes demoram décadas para ter retorno do investimento, o que o torna pouco atraente para um investidor capitalista nesse tipo de empreitada. Dessa forma, 
o mercado per se poderia não atender às necessidades de desenvolvimento do país, como ocorre em diferentes países com distintos graus de desenvolvimento. Nesses casos, BDs em diversos países atuam para suprir tais lacunas. A Alemanha faz isso por meio do seu congênere, o Kreditanstalt für Wiederaufbau (KfW), a Coreia do Sul possui seu Korean Development Bank (KDB), a China, o CDB, e assim por diante. Há mais de uma centena de BDs espalhados pelo mundo, com maior ou menor grau de eficiência e eficácia.

Muito além da questão do custo do dinheiro, suas determinantes e distorções - que são também fundamentais - persistem, outrossim, na questão dos arranjos institucionais que permitem melhor eficiência locativa de recursos, com maiores e melhores externalidades econômicas e impactos sociais e sobre a produtividade agregada. Portanto, há que se aprofundar a discussão qualitativa sobre como e em quais setores nosso principal BD, o BNDES, deve atuar, questionando-se também sobre como deve captar recursos, entre outras questóes, tendo em vista impactos econômicos horizontais sobre produtividade e competitividade amplas, considerando o custo-efetividade e o custo de oportunidade à sociedade.

\section{REFERÊNCIAS}

COSTA, R. T. da. Perspectivas e projeçôes para a economia e o mercado de capitais. Revista RI, n. 204, jun./jul. 2016. Disponível em: <https://goo.gl/mFMKyY>.

DE NEGRI, J. A.; ARAÚJO, B. C.; BACELETTE, R. Financiamento do desenvolvimento no Brasil. Brasília: Ipea, 2018. IPEA - INSTITUTO DE PESQUISA ECONÔMICA APLICADA. Desafios da naçáo. Brasília: Ipea, 2018. v. 1.

ROCCA, C. Financiamento das empresas e do investimento no Brasil. In: SEMINÁRIO FINANCIAMENTO DAS EMPRESAS E DO INVESTIMENTO NO BRASIL, 2017, Rio de Janeiro. Anais... Rio de Janeiro: [s.n.], 2017. 